Original Article

\title{
Percutaneous Drainage of Abdominal Collections under Imaging Guide
}

\author{
Nasser M. Meazher* \\ Mohammed A. Mahdi ** \\ Safa M. Al Obaidi***
}

\author{
FICMS \\ FICMS \\ FRCS, FACS
}

Abstract:

JFac Med Baghdad 2017; Vol.59, No .1

Receive Nov. 2016

Accepted Feb. 2017

Background: One of the most significant advances in the treatment of intra-abdominal collections during the past 2 decades has been the introduction of image-guided therapy with percutaneous catheter drainage. The development of improved imaging modalities, together with broad-spectrum antibiotics and soft drainage catheters, has changed the treatment of collections that previously required an urgent operation. Disease processes that have traditionally been treated with open surgical drainage and debridement can now be resolved with percutaneous catheter drainage and antibiotics. In selected cases, this will allow for better preparation of the patient for a later elective and definitive operation.

Objective: Highlight the outcome, safety and effectiveness of percutaneous drainage procedure of abdominal collections performed under imaging guide.

Patients and Methods: Forty one patients were referred from surgical wards and emergency department after diagnosing abdominal collections. Then each case discussed with radiologist to determine the route and type of catheter and imaging modality for guidance (ultrasound and/or computerized tomography). The size and site of the collections were estimated along with the most suitable approach and angle of catheter insertion. A safe drainage route was identified avoiding solid organs and bowel.

Results: Percutaneous drainage of 41 abdominal collections under imaging control was carried out in 41 patients during a one year period. No complications resulted from the procedure itself. Percutaneous drainage was sufficient to drain the collections in 35 cases (no further surgery is needed). Of those who require surgery ( 5 patients), the procedure considered to be as a temporary measure. One case was diagnosed as sero-mucinous tumor of bowel.

Conclusion: Percutaneous drainage of abdominal collections is a safe, effective and minimally invasive alternative approach to formal surgical drainage.The advantages include: the drainage can be done under local anesthesia, diagnosis and treatment can be achieved simultaneously in radiological department.

Key words; Percutaneous drainage, Imaging guide, Collection.

Introduction:

Percutaneous catheter drainage (PCD) is now standard therapy for patients with intraabdominal collections who do not have other indications for surgery. The vast majority of collections can be managed with an appropriately sized and positioned catheters[1]. Percutaneous drainage is defined as the placement of a catheter using imaging guidance to provide continuous drainage of a fluid collection. [2]. Percutaneous aspiration is defined as evacuation of a fluid collections using either a catheter or needle, with removal of the catheter or needle immediately after the aspiration [3,4]. Contraindications of percutaneous drainage: Common contraindications include uncorrectable coagulopathy and the absence of a safe percutaneous path access the collection $[4,5,6]$. Catheter insertion technique: There are two methods for introducing a catheter into collections:

Trocar technique:The trocar technique involves a catheter

\footnotetext{
*Dept. of medicine college/kufa university,dr.nasir81@yahoo.com.

**AlNajaf health care center /AL sadder medical city.

***Dept. Medicine college /university of Jabber Ibn Hayan.
}

mounted on a sharp trocar and inserted into the abscess or collection with a guiding needle [5,7]. Seldinger technique: The Seldinger technique involves the insertion of a hollow needle into the abscess cavity or the collection and the placement of a guide wire through the needle to create a percutaneous path for a drainage catheter $[5,7]$.

\section{Aim of the study:}

Evaluate the outcome of percutaneous drainage procedure of intraabdominal abscesses and fluid collections performed under imaging-guide and the effectiveness as alternative to open surgical drainage.

\section{Patients and Methods:}

From October 2013 to November 2014, 41 patients were referred from surgical wards and emergency department in Baghdad teaching hospital and Al-Sadder teaching hospital after diagnosing abdominal collections. Then each case discussed with same radiologist in each center to determine 
the route and type of catheter and imaging modality for guidance (US and/or CT). Detection of the collections by US only was done in 30 of 41 patients, while CT scanning was needed in addition to US in 11 patients. The size and site of the collections were estimated along with the most suitable approach and angle of catheter insertion. A safe drainage route was identified avoiding solid organs and bowel. The procedures was done in radiology department as outpatient procedure in 41 patients, some of them admitted to the surgical ward for followup and management (rehydration and iv antibiotics). All procedures were done under local anesthesia using Lidocaine 1\%( 5-10 ml) without adrenaline and without sedation. Aspiration was done using wide bore needle and the sample isolated and sent for culture and sensitivity, AFB, biochemistry and cytology. The catheter was then sutured directly to the skin and left in situ until free drainage stopped and follow-up ultrasonography showed resolution of the collections. Suprapubic catheter used for superficial collections with safe route, chest tube was used for thick collections specially in the right subphrenic abscesses and PNS catheter was used for deep collections with critical route, so we use Seldinger technique for placing the catheter. Needle aspiration was done for two patients and improved completely without need for catheter insertion. Initial drainage usually ended with complete evacuation, then the patients were followed daily by US, and catheter care to ensure patency (Irrigation of the catheter was done once daily with normal saline to ensure tube patency). Additional procedures (ERCP and stenting) was required for those with history of bile leakage (seven patients needed ERCP and one of them required stenting of right hepatic duct).Catheters was removed after few days to weeks depending on certain criteria.

Criteria for removal of the drain include

(1) Clinical resolution of septic parameters, including patient well-being, normal temperature, and leukocyte count; (2) Minimal drainage from the catheter; and

(3) Evidence of the resolution of the collections depending on imaging study.

\section{Results:}

Forty one patients were included in the study from Baghdad teaching hospital and AL- Sadder teaching hospital between October 2013 to November 2014; all of them had abdominal collections. They were 23 females and 18 males with age range ( 5 to 75 ) years. The patients had either postoperative or primary collections; 34 patients had postoperative collections mainly following cholecystectomy, laparotomy (trauma and perforated viscus), hydatid cyst and appendicectomy(Table 1); 6 patients had primary collections mainly pyogenic liver abscess. One case was colonic tumor and misdiagnosed as appendicular abscess.
Table 1: Distribution of the post-operative cases according to the primary operation or procedure:

\begin{tabular}{cccc}
\hline Operation & $\begin{array}{c}\text { No. of } \\
\text { patients. }\end{array}$ & $\begin{array}{c}\text { \% of postop. patients. } \\
\text { (34 patients.) }\end{array}$ & $\begin{array}{c}\% \text { of Total } \\
\text { (41 patients.) }\end{array}$ \\
\hline Cholecystectomy & 15 & $44.11 \%$ & $36.58 \%$ \\
\hline Laparotomy $*$ & 4 & $11.76 \%$ & $9.75 \%$ \\
\hline Hydatid Cyst surgery & 4 & $11.76 \%$ & $9.75 \%$ \\
\hline Appendicectomy & 4 & $11.76 \%$ & $9.75 \%$ \\
\hline Colonic surgery & 1 & $2.94 \%$ & $2.43 \%$ \\
\hline Hysterectomy & 2 & $5.88 \%$ & $4.87 \%$ \\
\hline Gastrectomy & 1 & $2.94 \%$ & $2.43 \%$ \\
\hline Whiple's procedure & 1 & $2.94 \%$ & $2.43 \%$ \\
\hline Hernia repair & 1 & $2.94 \%$ & $2.43 \%$ \\
\hline Trauma** & 1 & $2.94 \%$ & $2.43 \%$ \\
\hline Total & 34 & & $82.92 \%$ \\
\hline
\end{tabular}

Laparotomy following trauma and perforated viscus;

Trauma due to motor vehicle accident(blunt trauma).

Locations of collections on diagnostic imaging study were mainly Rt. Subphrenic and subhepatic ; pelvic, retroperiteneal and RIF collections ( Table 2).

Table 2: Location of collections on Diagnostic Imaging Study:

\begin{tabular}{ccc}
\hline Location & $\begin{array}{c}\text { No. of } \\
\text { patients.* }\end{array}$ & $\begin{array}{c}\% \text { of Total } \\
(41 \text { patients. })\end{array}$ \\
\hline Right subphrenic/subhepatic & 23 & $56.09 \%$ \\
\hline Pelvis/perirectal & 12 & $29.26 \%$ \\
\hline Retroperitoneal (perinephric/psoas) & 4 & $9.75 \%$ \\
\hline Right lower quadrant & 3 & $7.31 \%$ \\
\hline Left lower quadrant & 1 & $2.43 \%$ \\
\hline Abd. Wall & 1 & $2.43 \%$ \\
\hline
\end{tabular}

* some patients have multiple collections .

The drained materials were mainly pus or bile and one was serous which was then diagnosed as cystic adenocarcinoma as shown in (Table3).

Table 3: Drained material:

\begin{tabular}{ccc}
\hline Drained material & No. of patients. & \% of Total (41 patients.) \\
\hline Pus & 24 & $58.53 \%$ \\
\hline Bile & 12 & $29.26 \%$ \\
\hline Blood & 2 & $4.87 \%$ \\
\hline Lymph & 1 & $2.43 \%$ \\
\hline Small bowel content & 1 & $2.43 \%$ \\
\hline seromucinous & 1 & $2.43 \%$ \\
\hline Total & 41 & $100 \%$ \\
\hline
\end{tabular}

*Anastomosis leak

Twenty eight patients were improved completely after drainage of their collections $(70 \%)$.Seven patients with bile leak needed further interventional procedures (ERCP and Sphinecterotomy) and one of them was required stenting of Rt. hepatic duct(17.5\%). Five patients did not improve after PCD and need surgical intervention(12.5\%) ;one patient with peritoneal mucinous carcinomatosis died after 6 months; 
Table 4 : Details of [5] cases required surgery(PCD failed):

\begin{tabular}{ccccc}
\hline Case no. & Anatomical Site & Pathology & Duration & Reason for surgery \\
\hline 1. & Rt. subphrenic & Colorectal carcinoma & 14 days & persistent discharge(residual necrotic tumor \\
\hline 2. & Abdominal wall & Hernia mesh repair & 21 days & persistent discharge (Foreign body) \\
\hline 3. & Lt. iliac fossa & Laproscopic cholecystectomy & 4 days & Perforated viscus \\
\hline 4. & Pelvic & hysterectomy & 17 days & Septated collection \\
\hline 5. & Rt. subphrenic & Liver hydatid cyst (postop.) & $\mathbf{2 0}$ days & Insufficient drainage \\
\hline
\end{tabular}

\section{Discussion:}

The use of radiologic guidance techniques for the diagnosis and aspiration of intraabdominal collections was described as early as $1977[8,9]$. In a 1981 review, Gerzof described radiologic placement of drainage catheters in 67 patients with intra-abdominal abscesses with satisfactory drainage of 86 percent [10]. In our study, detection of the collections by US only was in 30 of 41 patients ( $73.1 \%$ ), while CT scanning was needed in addition to US in $11(26.8 \%)$ of patients, Ultrasound accuracy has also been quite favorably reported by numerous authors for fluid collections detection[11]. Knochel et al [12] reported a sensitivity of $82 \%$ and a specificity of $94.5 \%$, and Carroll et al [13] reported an overall accuracy of $84 \%$. Observational studies from a number of centers have shown it to be a safe effective alternative to surgical intervention, with equivalent success rates, comparable mortality (10-20\%) and morbidity $(\sim 25 \%) \quad[14,15]$. Inspite of the $100 \%$ technical success in the procedure, which is exactly the same as in Marianne E et al study [16], failure of drainage in our study occurred in 5 patients( $12.5 \%$ ), compared to Kumar et al study [17], in which 3\% failed to improve and underwent operative intervention, and to Lagana et al $8.4 \%$ [18]. Others reports include Haage et al with 14\% [19], Lang et al with $23 \%$ [20], Jaques et al with $34 \%$ (15\% failure and $18 \%$ partial success) [21]. In our study, 24 cases were abscess collections and PCD was done; 19 cases improved completely and 5 cases need surgical interventions(success rate was $79 \%$ and failure rate was $21 \%$ ). These results are similar to the results achieved by (Bakal CW. et al and Cinat ME. et al) [22,2] . Other circumstances such as necrotic-infected tumor have a lower success rate for percutaneous drainage and early consideration for surgical intervention [22]. Seeto RK et al mentioned needle aspiration and percutaneous catheter drainage

of abscesses have similar mortality rates; however, recurrence rates and the requirement for surgical intervention may be greater in those who undergo aspiration alone[23]. Needle aspiration is less invasive, less expensive, and avoids all of the complications associated with catheter care. Giorgio and colleagues[24] reported a series of 115 patients with a $98.3 \%$ success rate for needle aspiration, no mortality, and no procedure-related morbidity. A randomized controlled trial by Rajak et al [25] in 1998 compared percutaneous needle aspiration to catheter drainage and also found no major complications and no deaths.

In our study we did aspiration in two cases and was improved completely.Significant postoperative bile leaks occur in approximately 0.8 to 1.1 percent of patients $[26,27]$. In our study, bile was drained in $12(29.2 \%)$ of the cases, seven of them need further intervention( ERCP, and stenting in one pt.) Gianpaolo Carrafiello et al had shown interventional radiological procedures are effective in the emergency management of surgical bile duct injury since they are minimally invasive and have a high success rate and a low incidence of complications compared to the more complex and dangerous surgical or laparoscopic options and can be considered as lifesaving procedure [28] .

\section{Conclusion:}

Percutaneous drainage of abdominal collections is a safe and effective alternative to formal surgical drainage. The advantages include the fact that drainage takes place under local anaesthesia, which is beneficial especially when the patient's general condition is too poor for the administration of a general anaesthetic. PCD is a good alternative for open procedures and can be repeated as necessary.

\section{Author contributions:}

Prof. Safa M. Al Obaidi: study conception and design. data interpretation and analysis, revision.

Dr. Nasser Madhlom Meazher: study conception and design. data interpretation and analysis,drafting of manuscript and revision.

Dr. Mohammed Abdalameer Mahdi: study design,data interpretation and analysis,.

\section{References:}

1. Shuvro Roy-Choudhury. D.A. Gervais and T. Sabharwal. editors. Drainage of Abdominal Fluid Collections. In: Gervais, Debra A., Sabharwal, Tarun, editors. Interventional Radiology Procedures in Biopsy and Drainage. London: Springer-Verlag Limited;2011. P. 99-109.

2. Bakal $C W^{1}$, Sacks D, Burke DR, Cardella JF, Chopra 
PS, Dawson SL, Drooz AT, Freeman $N$, Meranze SG, Van Moore A Jr, Palestrant AM, Roberts AC, Spies JB, Stein EJ, Towbin R.Quality Improvement Guidelines for Adult Percutaneous Abscess and Fluid. J Vasc Interv Radiol. 2003 Sep;14(9 Pt 2):S223-5..

3. Golfieri $R^{1}$, Cappelli A. Computed tomography-guided percutaneous abscess drainage in coloproctology: review of the literature. Tech Coloproctol. 2007 Sep;11(3):197-208. Epub 2007 Aug 3.

4. Curtis W.Bakal, David Sacks, Dana R.Burker et al :Quality improvement guidelines for adult percutaneous abscess and fluid drainage.J Vasc Interventional Radiol .2003; 14: 223225.

5. Duszak RL, Jr, Levy JM, Akins EW, et al. Percutaneous catheter drainage of infected intra-abdominal fluid collections. American College of Radiology. ACR Appropriateness Criteria. 2000; 215:1067-1075.

6. Jennifer L.lynch,Daniel L. Overdeck et al. Percutaneous Abdominal and Pelvic Abscess Drainage Technique.Seminars in Interventional Radiology.2003; 20(3): 185-193

7. Peter R.Mueller ;The Evolution of Image- Guided Percutaneous Abscess Drainage. Seminars in Interventional Radiology 2003 ;20(3);171-176

8. Gerzof SG, Robbins AH, Birkett DH, Johnson WC, PUgatCh $R D$, Vincent ME. Percutaneous Catheter Drainage of Abdominal Abscesses Guided by Ultrasound and Computed Tomography.AJR .1979 Jul;133(1):1-8

9. Haaga JR, Alfidi RJ, Havrilla TR, et al. CT detection and aspiration of abdominal abscesses. AJR Am J Roentgenol. 1977; 128:465-74. [PubMed: 402843]

10. Gerzof SG, Robbins AH, Johnson WC, et al. Percutaneous catheter drainage of abdominal abscesses: a five-year experience. $N$ Engl J Med. 1981; 305:653-7. [PubMed: $7266601]$.

11.Bergman JJ, van den Brink GR, Rauws EA, et al. Treatment of bile duct lesions after laparoscopic cholecystectomy. Gut. 1996; 38:141.

12.Knochel,J.O.,Koehler,P.R.,Lee,T.G. Diagnosis of Abdominal Abscess with Computerised Tomography and U/S . Radiology.1980; 137:427

13. Carroll B, Silverman PM, Goodwin DA, McDougall I R: Ultrasonography and Indium 111 white blood cell scanning for the detection of intraabdominal abscesses. Radiology. 1981;140:155.

14. Olak J, Christou NV, Stein LA, et al. Operative vs percutaneous drainage of intra-abdominal abscesses. Comparison of morbidity and mortality. Arch Surg. 1986; 121:141.

15. Hemming A, Davis NL, Robins RE. Surgical versus percutaneous drainage of intra-abdominal abscesses. Am J Surg. 1991; 161:593.

16. -Marianne E,Cinat,Samuel E.Wison,Adnan M.Din
Determinants for successful percutaneous image-guided drainage of intraabdominal abscesses. Arch Surg .2002; 137:845-849

17. Ravin R,Kumar .Justin T.Kim,Jansa.S et al. Factors Affecting the Successful Management of Intra-abdomonal Abscesses with Antibiotics and the need for Percutaneous Drainage .Disease of the Colon andRectum.2006;38(2):183189

18. D Lagana, G. Garrafiello, M. Mangini et al . Imageguided percutaneous treatment of abdominal-pelvic abscesses: a 5-year experience. Radiol med .2008; 113 : 9991007(abstract)

19.Haaga JR. Imaging Intraabdominal Abscesses and Nonoperative Drainage Procedures World J. Surg. 1990;14: 204-209.

20. Lang , E.K, Springer, J. F. Bulch,R.J et al.Abdominal abscess drainage under radiologic guidance : Causes of failure. Radiology. 1986; 159:329

21. Jaques, $P$. ,Mauro ,M. ,Safrit ,H. et al.Features of intraabdominal abscess.Am J.Roentgenol.1986;146:1041

22.Cinat ME, Wilson SE, Din AM. Determinants for Successful Percutaneous Image-Guided Drainage of Intraabdominal Abscess. Arch Surg. 2002; 137:845-849

23. Seeto RK, Rocky DC. Pyogenic liver abscess: Changes in etiology, management, and outcome. Medicine. 1996; 75:99113.

24. Giorgio A, Tarantino L, Mariniello $N$, et al. Pyogenic liver abscess: 13 years of experience in percutaneous needle aspiration with U/S guidance. Radiology. 1995; 195:122124.

25. Rajak CL, Gupta S, Jain S, et al. Percutaneous treatment of liver abscesses: needle aspiration versus catheter drainage. Am J Roentgen. 1998; 170:1035-1039.

26.Trondsen E, Ruud TE, Nilsen BH, et al. Complications during the introduction of laparoscopic cholecystectomy in Norway. A prospective multicentre study in seven hospitals. Eur J Surg. 1994; 160:145.

27. Barkun AN, Rezieg M, Mehta SN, et al. Postcholecystectomy biliary leaks in the laparoscopic era: risk factors, presentation, and management. McGill Gallstone Treatment Group. Gastrointest Endosc .1997; 45:27

28. Gianpaolo Carrafiello, Domenico Lagana, Massimilliano Dizonno et al Emergency percutaneous treatment in surgical bile duct injury .Emergency Radiology. 2008; 15 : 335-341. 